and it is inferred that the head ought to merge more gradually into the main body of the member than is at present the common practice. The applications of optical science may possibly be of use, therefore, in the design of structures and machines, as these examples indicate, especially where new problems arise, such as in the design and construction of aeroplane stays and struts,

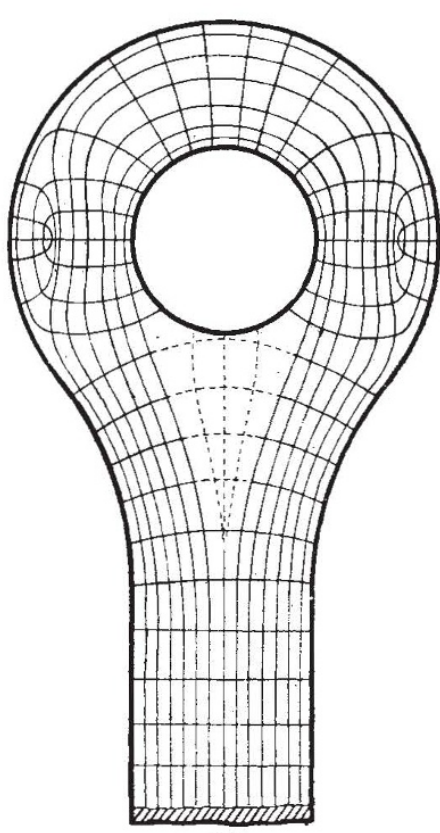

(a)

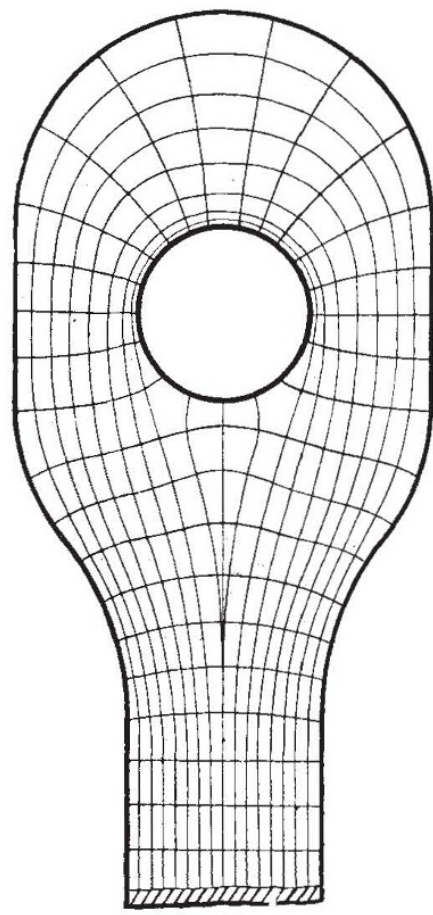

(b)

Fig. 6.-Lines of princifal stress in two standard types of eye-bars used in bricge structures.

where a poorly designed member adds weight without coresponding strength, and may by its failure result in a serious loss of life.

\section{E. G. Coker.}

\section{THE WARFARE AGAINST TUBERCU- LOSIS.}

DROF. METCHNIKOFF delivered the Lady 1 Priestley Memorial Lecture for I9I2-I3 under the auspices of the National Health Society at the Royal Society of Medicine on November 29. Sir Crichton Browne presided, and among others present were Sir Thomas Barlow, President of the Royal College of Physicians, Sir Rickman Godlee, President of the Royal College of Surgeons, Sir Ray Lankester, Sir James Goodhart, Sir Almroth Wright, Sir Lauder Brunton, Dr. and Mrs. Priestley, Sir Edward and Lady Busk, and Mr. and Mrs. Stephen Paget.

The subject of the lecture was the campaign against tuberculosis, and subjoined is a summary of Prof. Metchnikoff's remarks.

Although tuberculosis had been regarded by some as contagious, particularly in southern countries, it was a French observer, Villemin, who fifty years ago showed that the disease can be transmitted by inoculation. Then in I88I Robert Koch discovered the causative germ, the tubercle bacillus. Several species, or at least strains, of the tubercle bacillus are known, and piscian, avian, and mammalian forms are now recognised, and the bacilli of man and of bovine animals also exhibit differences, but the variety peculiar to man is the great source of human tuberculosis.

Tuberculosis is a common disease, but does not kill rapidly, and may take months or even years before ending fatally. 'The bacillus causes the formation in the tissues of cellular nodules, the tubercles, in which large multi-nucleated cells, the "giant" cells, are present, and perform a defensive function, ingesting and destroying tubercle bacilli, so that in favourable cases the nodules heal and disappear, or become fibrous or calcareous and inert.

There is evidence that tuberculous infection is exceedingly frequent, for the healed or calcareous tubercles are very common at the apex of the lung of those dying from any cause, and can also be demonstrated by applying the Pirquet test. This consists in applying tuberculin to a scarified patch on the skin, which gives rise in tuberculous persons to an inflamed red spot, and 90 per cent. of the adult European population is shown in this way to have been infected with the tubercle bacillus, yet only $x_{5}$ per cent. die of tuberculosis. Among the Kalmuk Tartars, studied by Prof. Metchnikoff, however, tuberculosis is rare, but this is not due to a natural insusceptibility, for Kalmuk youths residing in towns in Russia for purposes of education contract tuberculosis freely.

Attempts to cure tuberculosis by drugs, diet, climate, serum, and tuberculin were discussed, but the conclusion was expressed that, though some of these are helpful, no real remedy or sure treatment for tuberculosis has been found. Nevertheless, the death-rate from tuberculosis in large cities, such as London, Hamburg, and Copenhagen, is steadily declining, and this result Prof. Metchnikoff ascribes to unconscious inoculation by infection with mild or benign strains of the tubercle bacillus, which serves to protect against the virulent organism. It is on these lines that Prof. Metchnikoff believes that the stamping out of tuberculosis is to be attempted, viz., the discovery or artificial production of strains of the tubercle bacillus having but slight virulence, which, on inoculation in suitable doses, will serve to protect the inoculated against the virulent organism.
R. T. H.

NO. 2249, VOL. go] 